\title{
Striking Century-Long Changes in Marine Benthos
}

\author{
Rutger Rosenberg \\ Department of Biology and Environmental Science—Kristineberg, University of Gothenburg, Gothenburg, \\ Sweden \\ Email: rutger.rosenberg@bioenv.gu.se
}

Received 28 July 2014; revised 25 August 2014; accepted 21 September 2014

Copyright (C) 2014 by author and Scientific Research Publishing Inc.

This work is licensed under the Creative Commons Attribution International License (CC BY).

http://creativecommons.org/licenses/by/4.0/

c) (i) Open Access

\begin{abstract}
One of the oldest published records of benthic fauna was made in 1893 by dredging along transects from soft bottoms, sand and shell debris to rocky bottoms in an archipelago at the Swedish Skagerrak coast. Three of the transects were revisited in $\mathbf{2 0 1 0}$ and then fewer taxa were recorded and the shared species between sampling dates at the transects were only between $8 \%$ and $12 \%$. The main causes for the drastic changes are suggested to be large-scale eutrophication changing the vegetation composition and variation of climatic factors.
\end{abstract}

\section{Keywords}

\section{Marine Benthos}

\section{Introduction}

Substantial changes in marine ecosystems have been reported repeatedly over the last decades. The reason is a combination of many factors. For example, Jackson et al. [1] concluded that ecological extinction caused by overfishing precedes all other pervasive human disturbance to coastal ecosystems, and Pauli et al. [2] reported a global loss of top predatory fish by fishing-down-the-food-web, which affects the function of the ecosystem. These selected studies show that man's activities have far-reaching consequences on the functioning not only of the coastal marine ecosystem but also in the ocean. Eutrophication has increased globally over more than half a century, and in association with extensive nutrient input, dead zones have spread exponentially in coastal and enclosed seas [3]. Thus, there is substantial evidence that marine ecosystems are under pressure and that changes have been going on for a long time.

One of the greatest challenges to environmental science is to analyse and establish the consequences of how much culture and other activities of mankind have changed the biosphere. Ultimately, a sound balance between 
biodiversity and functions between various environmental properties is a prerequisite for the maintenance of a sustainable global ecosystem. So, how do scientists determine when an ecosystem is in disorder? How do we analyse and establish when ecosystems have changed from a pristine state to conditions that might lead to significant negative consequences? For such judgements scientists need hard-core scientific data from centuries back. In this paper the focus is on century-long drastic changes in a regional marine ecosystem.

To analyse site-specific local and regional long-term changes in marine ecosystems, the composition of benthic macrofaunal communities is particularly suitable as benthic animals tend to occupy the same habitat for several years, and the benthic communities show rather predicable structural changes in relation to various environmental disturbances according to the Pearson and Rosenberg [4] paradigm. Petersen [5] [6], a pioneer in benthic quantitative ecology, has already demonstrated about a century ago that benthic animals in the Skagerrak-Kattegat area re-occurred in habitat-specific associations. To analyse possible long-term changes in that area, several of Petersen's stations were re-visited about 70 years later, and significant changes in benthic community composition were found between the sampling dates [7] [8].

The Swedish Skagerrak coast is one area that locally and regionally has been subject to eutrophication and hypoxia over the last decades, which has lead to structural changes in the ecosystem [9]. In the present study made in 2010 in one area of the Skagerrak archipelago, the composition of benthic fauna is compared with a study conducted already in 1893. That investigation was performed by another pioneer, Hjalmar Théel [10], the director of one of the oldest marine field stations in the world, Kristineberg Zoological Station in Fiskebäckskil, Sweden, founded in 1877. Théel's data must be one of the oldest published records of the faunal composition in costal waters of defined depth transects. The sampling methods were qualitative dredging and included a mosaic of samples from soft mud, sand and shell debris to rocks with vegetation. Théel wrote in his publication that he wanted to publish his records of the fauna for later analyses regarding possible temporal changes in this archipelago.

\section{Material and Methods}

Théel [10] sampled about 20 different transects in the vicinity of the Gullmarsfjord and outside in the archipelago, and he used 17 different taxonomists for help with the identification of the animals. He described the sampling technique as follows: a rope of two to three hundred metres or more was attached to land on a rock. The boat was rowed out in a defined direction until the rope ended. Here the dredge was lowered and the depth recorded. The man in the front of the boat will now hale the boat and dredge to where the rope was attached. Thus, dredging began on deep soft mud and ended up on shallow rocks with attached algae. Théel did not mention the size of the dredge. I selected a small rectangular dredge with the frame measuring $46 \times 19 \mathrm{~cm}$ and $10 \times 10 \mathrm{~mm}$ mesh sizes. The larger old dredges stored at the research station seemed too heavy to be hauled by rowing.

The following locations were re-visited and the directions and depth records where the dredge was lowered to the seabed are from Théel (Figure 1).

Flatholmen, NE point towards Humlesäcken, maximum depth $45 \mathrm{~m}$.

Bonden, the rope was attached just south of the harbour and dredging was done in NE or NNE direction, maximum depth $25 \mathrm{~m}$.

Spättan is a skerry with a sea marker (still present). Dredging was made in direction towards Bondhålet (a small bay on Blåbergsholmen), maximum depth $30 \mathrm{~m}$.

The sampling date was in June 1893 for Flatholmen. Sampling dates for the other localities were not given. The recent sampling was made on 2 June 2010. There was no wind that day and the sea was flat allowing the R/W Oscar von Sydow (14 m long) to operate very close to the rocks, and the dredge was hauled all the way up to the surface along the rock side. Dredging speed was about 1 knot.

The sea level (tidal) difference in the Swedish Skagerrak coast is less than $25 \mathrm{~cm}$, salinity in the studied areas is around 20 to 25 down to the halocline at about $15 \mathrm{~m}$ depth, and below that depth the salinity is approximately 33. Temperature at the surface can vary between about $2^{\circ} \mathrm{C}$ in winter and $18^{\circ} \mathrm{C}$ in summer, and at $30 \mathrm{~m}$ temperature varies between $4^{\circ} \mathrm{C}$ and $14^{\circ} \mathrm{C}$ [11].

Taxonomic identity, nomenclature and association of different species to different habitats (hard bottom, sand and shell debris and soft bottom) were done after Hansson [12]. The scientific names have changed over time for several species. Thus, species identity was updated and corrected by using modern taxonomic literature and the Internet. 


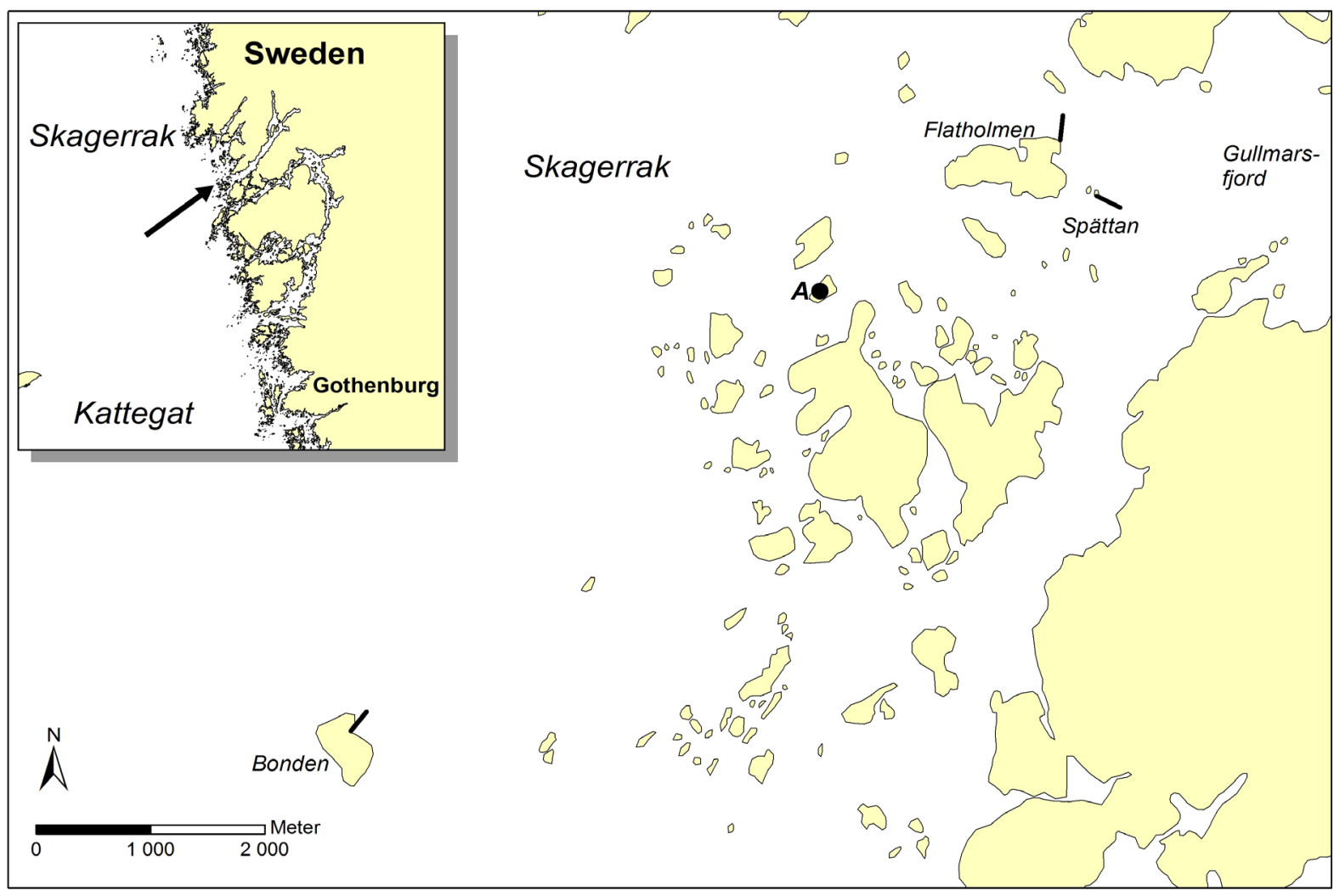

Figure 1. Map of the studied area at the Swedish Skagerrak coast. The three transects where dredging was performed are indicated at Bonden, Spättan and Flatholmen. The island where the depth distribution of macroalgae was investigated by Johansson et al. [17] is marked with A.

\section{Results}

Number of benthic taxa found in different animal groups is shown in Table 1. Total number of taxa found in 1893 and 2010 was 107 and 68, respectively. The three dominant taxonomic groups at both sampling dates were molluscs, echinoderms and polychaetes. In the outer archipelago at Bonden, the total number of taxa was lowest and similar at both sampling dates, 29 and 27, whereas the numbers were greater in 1893 at Spättan (47) and Flatholmen (50) compared to in 2010 (29 and 31).

Comparing the number of taxa shared at the two sampling dates at Bonden, Spättan and Flatholmen resulted in numbers of 4, 8 and 6 taxa, respectively. Similarly the percentage of shared taxa was 8, 12 and 8, respectively. If only echinoderms and molluscs were selected for analysis, as they often have a hard skeleton and a large size and therefore are comparatively easy to recognise in the samples, the following percentages of shared taxa were calculated: for echinoderms $(n=20), 5 \%, 15 \%$ and 5\%, respectively and for molluscs $(n=55), 4 \%, 4 \%$ and $2 \%$, respectively. If species were classified into the habitat they primarily are associated with, $48 \%$ were associated with hard bottoms, 31\% with soft bottoms and 21\% with shell debris or sand. Some species/taxa were not classified because lack of knowledge or they could be associated with more than one of these classifications.

The great changes between 1893 and 2010 occurred for species/taxa associated with hard bottoms, where 38 taxa were lost and 28 new records ( 7 were the same). In comparison 21 were lost and 9 new records ( 3 the same) associated with shell debris and sand, and 24 were lost and 12 were new records (11 the same) on soft bottoms.

Species occurring at both sampling dates and at several transects were the starfish Asteropecten irregularis, the bivalve Timocleia ovata, the anthozoans Alcyonioum digitatum and the cup-coral Caryophyllia smithii. Notably, the lancelet Brachiostoma (Amphioxus) lanceolatum was recorded at Bonden at both sampling dates.

\section{Discussion}

One of the great challenges in environmental scientific work is to detect significant changes in the ecosystem 
Table 1. Number of taxa found of different animal groups in 1893 (from Théel [4]) and 2010 at the localities Bonden, Spättan and Flatholmen at the Swedish Skagerrak coast.

\begin{tabular}{|c|c|c|c|c|c|c|c|c|}
\hline & \multicolumn{2}{|c|}{ Bonden } & \multicolumn{2}{|c|}{ Spättan } & \multicolumn{2}{|c|}{ Flatholmen } & \multicolumn{2}{|c|}{ Total No Taxa } \\
\hline & 1893 & 2010 & 1893 & 2010 & 1893 & 2010 & 1893 & 2010 \\
\hline Anthozoa & 2 & 1 & 4 & 3 & 6 & 4 & 10 & 5 \\
\hline Nematoda & 2 & & & & & & 2 & \\
\hline Nemertini & 1 & & & & 1 & 1 & 1 & 1 \\
\hline Polychaeta & 5 & 4 & 9 & 6 & 2 & 7 & 15 & 16 \\
\hline Crustacea & 1 & 4 & 5 & 3 & 1 & 4 & 6 & 7 \\
\hline Echinodermata & 4 & 5 & 10 & 4 & 10 & 5 & 18 & 8 \\
\hline Mollusca & 13 & 8 & 17 & 10 & 17 & 5 & 39 & 21 \\
\hline Cephalocordata & 1 & 1 & & & & & 1 & 1 \\
\hline Tunicata & & 2 & & 2 & 4 & 2 & 4 & 3 \\
\hline Bryozoa & & 2 & & & 2 & 3 & 2 & 4 \\
\hline Porifera & & 1 & & & & & & 1 \\
\hline Sipuncula & & & 1 & & & & 1 & \\
\hline Priapulida & & & 1 & & & & 1 & \\
\hline Cnidaria & & & & 1 & 6 & & 6 & 1 \\
\hline Brachiopoda & & & & & 1 & & 1 & \\
\hline TOTAL & 29 & 27 & 47 & 29 & 50 & 31 & 107 & 68 \\
\hline
\end{tabular}

and to evaluate the causes and consequences of such changes. The countries within the European Union have set standards and criteria for their coastal waters to obtain a good or high status of the water quality (EU Water Framework Directive). For an accurate quality assessment it is important to define the structure of a rather pristine ecosystem, i.e. to establish a reference value equal to a station of rather undisturbed conditions and from which a disturbance can be scientifically established. The quality of the seabed is generally assessed by analysing the structural composition of the benthic fauna according to predicted changes along gradients of disturbance as presented in the Pearson-Rosenberg [4] paradigm. Even if this model suggests how an undisturbed benthic community may be structured, there are very few published data going back a century or more.

In the present investigation striking changes were found in animal composition between the years 1893 and 2010. The pattern of change between these dates was similar for the three sites with percentage taxonomic similarities of only between $8 \%$ and $12 \%$. If the generally long-lived and larger animals in the taxonomic groups echinoderms and molluscs were selected for analysis, the similarities between sampling dates did not improve, except for one site. The dissimilarity between sampling dates was, therefore, not caused by occasional presence of small and short-lived individuals only. What are then the causes for such great changes of the fauna and what can be learnt from other historical comparisons? Below some historical comparisons from the same regions are reported. They do not go back as far as in the present study, 117 years, but around 50 to 70 years and comparing the 1910's and 1920's with the 1970's and 1980's. All these studies show structural temporal changes, but not as striking as in the present study.

\subsection{Regional Historical Studies}

Before analysing the possible causes for the striking changes between the two studies, I give a brief background to more recent studies and changes in faunal composition that have been reported from the same region. Petersen [5] [6] was the first to introduce a grab for analysing the fauna in a quantitative way. Petersen did surveys in the Kattegat in 1911-1912 and in the Skagerrak in 1914. Twenty-four of Petersen's stations in the Kattegat were revisited in 1984 [7] and 23 stations in the Skagerrak including the Oslofjord [8]. The methods were similar using a $0.1 \mathrm{~m}^{2}$ Petersen grab and $1 \mathrm{~mm}$ sieves. Both these studies showed that the composition of the benthic communities had changed significantly. The cause of the changes was suggested to be a combination of organic enrichment from eutrophication and effects from demersal trawling.

The first quantitative benthic study in Swedish coastal waters was made in the years 1923 to 1926 by Molander [13] in four fjord areas in the Skagerrak. Twenty of these stations were re-visited in 1976 using the same 
Petersen grab and mesh size as described above [14]. Also this comparison demonstrated great differences between sampling dates. Two reasons were suggested for the differences: natural long-term changes and/or differences in how the samples were processed. If small sized species, which might have been overlooked in the early investigation, were excluded in the comparison, the differences in faunal composition were reduced.

Another early study in the area was made by Gislén [15], who was the first diver to investigate the qualitative and quantitative algal and faunal composition (epibioses) on rocky bottoms in the Gullmarsfjord in 1926. Gislén, in his publication [15], also presented a detailed historical contribution to the development of the early scientific investigations in Europe. The most extensive study, however, was made by dredging in the Kattegat and Skagerrak between 1921 and 1938 covering 440 stations [16]. There are no published historical comparisons concerning that investigation.

\subsection{Causes for the Striking Changes}

There are several possible explanations for the striking changes recorded between 1893 and 2010. However, no scientific platform based on historical data can give a comprehensive answer. The ecological processes that affect the composition of the organisms in a particular environment are manifold and interactive. The natural variability is one overriding factor, where differences in reproductive and recruitment success vary between years as a consequence of climate variability and competition between species. Already at the time of Théel's [10] investigations at the end of the 1800's - when the anthropogenic impact was low compared to today - he noted strong temporal variations in abundance of some soft-bottom species, particularly echinoderms. In the present investigation great changes were recorded for taxa associated with the three different habitats investigated. The changes were particularly great on hard bottoms where 38 taxa were lost between the sampling dates and 28 were new arrivals. Several of these taxa are known to be associated with macroalgae and in many cases dependent to the structure of the vegetation.

Johansson et al. [17] studied the depth distribution and species composition along three depth profiles on rocky habitats by diving in the same archipelago as in the present study (Figure 1, site A). They re-visited the areas in 1997 that were earlier studied in 1960 to 1961. They concluded that the abundance of filamentous algae on the rocks of the islands had increased over that time period, which they attributed to eutrophication. In 1994 to 1996 Pihl et al. [18] documented the distribution of green algal mats (mainly Cladophora and Enteromorpha) by combining aerial photography and ground truth sampling along most of the Swedish Skagerrak coast at 0 to 1 $\mathrm{m}$ depth. The algae were found at $60 \%$ to $90 \%$ of the investigated shallow soft bottom areas and covered $30 \%$ to $50 \%$ of the total areas investigated with impacts on the epibenthic fauna and fish composition [19]. Thus, these studies of macroalgae show that the algal composition has changed in the region because of eutrophication and created altered habitats for the associated fauna. Changes in shallow water vegetation from perennial algae to filamentous annual algae have negative implications for the foraging success of fish like cod and plaice [20]. These factors combined might be possible drivers for the long-term changes found in the present study, particularly as the greatest changes were found for animals associated to rocks and attached algae.

In another study of benthic fauna on soft bottoms in the Swedish Skagerrak archipelago, Rosenberg and Nilsson [9] showed general negative temporal changes over the last decades at 26 stations. These changes were attributed to negative oxygen conditions in association with detached vegetation, leading to organic enrichment and locally even anoxic conditions. Unlike in that study, no mass occurrence of drift algae was found in the present investigation. Rosenberg and Nilsson [9] showed that the benthic communities in that part of the Skagerrak archipelago were severely affected by anthropogenic disturbance that had worsened by time. As there are no significant local sources of pollution, the effects are suggested to be large-scale eutrophication.

East of the archipelago studied in the present investigation is the Gullmarsfjord (Figure 1), where oxygen in 1997 occasionally was depleted in the deeper parts (80 to $118 \mathrm{~m}$ ), and the benthic fauna was reduced and even eliminated in some deep areas. Following re-oxygenation of the near-bottom water the benthic communities were re-established within about two years to pre-hypoxic conditions regarding faunal structure [21]. This faunal successional process demonstrated that the recovery on these benthic communities could be predicted and that the natural variation was insignificant at that time. Thus, in deeper coastal waters, where the climatic variation is comparatively smaller, the variation in faunal numbers and composition are smaller than in shallow waters. Thus, it can be expected, as was indicated in the present study, that the greatest changes occurred near the surface. It is here the greatest seasonal and annual changes in temperature, salinity and wave exposure occur in boreal and 
temperate waters and, in addition, also riverine discharges of nutrients and other pollutants.

The studied areas were not likely to be affected by low oxygen as they are fairly exposed and neither by direct physical disturbance as demersal trawling is prohibited in the studied areas. The commercial fisheries have some effect on the fish composition, and this can have impact on the predation pressure and selection of the benthic fauna. This is, however not likely to have contributed in any significant way for the drastic changes.

It is difficult to exactly imitate methods used in earlier investigations. In the present investigation the dredge was dropped at the same depth and hauled in a direction reported by Théel [10]. The dredge was small and probably of similar size to that used by Théel. A larger dredge would have been difficult to operate with a rowing boat. Thus, the sampling technique is suggested to be similar without any drastic effect on the comparative result, and the dredge is supposed to have covered similar bottom stretches and areas in both investigations. The animals were picked on the boat deck and the amount of mud and vegetation could have had some influence on the numbers of species found. However, even if only large and firm animals were analysed and compared, the discrepancy in faunal composition between the two studies still remains. This suggests that differences in sorting and picking out the animals are not the solution to the drastic changes, but rather of minor importance.

\section{Conclusion}

Drastic changes were recorded in a number of species/taxa between the two sampling dates 1893 and 2010. The number of taxa recorded in 2010 was fewer at all three transects, and only between $8 \%$ and $12 \%$ of the taxa were the same between sampling dates. The greatest temporal changes were found for taxa associated with shallow hard bottoms, where the compositions of attached and fauna-associated macroalgae are indicated to have changed, most probably because of large-scale eutrophication and seasonal and annual natural variations in climatic factors. Trawling, low oxygen concentrations and differences in sampling techniques are suggested to have minor impact on the result. Spectacular species as the cup-coral Caryophyllia smithii and the lancelet Brachiostoma lanceolatum were recorded at both sampling dates. This shows that at least some species that could be regarded as sensitive to habitat change and disturbance were probably present in the same habitats over more than a century. Overall, the long-term changes observed in the present study coincide with similar trends of changes in faunal composition found in the region. However, the changes in the present study seem to be more drastic, and as there is no direct local anthropogenic disturbance further investigations are needed to evaluate the extent of other ecosystem changes and their consequences for ecosystem functioning.

\section{Acknowledgements}

I am grateful for taxonomic assistance by Stefan Agrenius (molluscs and polychaetes) and Matz Berggren (crustaceans). I thank Berne and Ursula for excellent research-ship performance.

\section{References}

[1] Jackson, J.B.C., Kirby, M.X., Berger, W.H., Bjorndal, K.A., Botsford, L.W., Bourque, B.J., Bradbury, R.H., Cooke, R., Erlandson, J., Estes, J.A., Hughes, T.P., Kidwell, S., Lange, C.B., Leinihan, H.S., Pandolfi, J.M., Peterson, C.H., Steneck, R.S., Tegenr, M.J. and Warner, R.R. (2001) Historical Overfishing and the Recent Collapse of Coastal Ecosystems. Science, 293, 629-637. http://dx.doi.org/10.1126/science.1059199

[2] Pauly, D., Christensen, V., Dalsgaars, J., Froese, R. and Torres Jr, F. (1998) Fishing Down Marine Food Webs. Science, 279, 860-863. http://dx.doi.org/10.1126/science.279.5352.860

[3] Diaz, R.J. and Rosenberg, R. (2008) Spreading Dead Zones and Consequences for Marine Ecosystems. Science, 321, 926-929. http://dx.doi.org/10.1126/science.1156401

[4] Pearson, T.H. and Rosenberg, R. (1978) Macrobenthic Succession in Relation to Organic Enrichment and Pollution of the Marine Environment. Oceanography and Marine Biology-An Annual Review, 16, 229-311.

[5] Petersen, C.G.J. (1913) Valuation of the Sea. 2. The Animal Communities of the Sea Bottom and Their Importance for Marine Zoogeography. Report from the Danish Biological Station, 21, 1-68.

[6] Petersen, C.G.J. (1915) On the Animal Communities of the Sea Bottom of the Skagerrak, the Christiania Fjord and the Danish Waters. Report from the Danish Biological Station, 23, 1-28.

[7] Pearson, T.H., Josefson, A.B. and Rosenberg, R. (1985) Petersen’s Benthic Stations Revisited. I. Is the Kattegat Becoming Eutrophic? Journal of Experimental Marine Biology and Ecology, 92, 157-206.

http://dx.doi.org/10.1016/0022-0981(85)90094-2 
[8] Rosenberg, R., Gray, J.S., Josefson, A.B. and Pearson, T.H. (1987) Petersen’s Benthic Stations Revisited. II. Is the Oslofjord and Eastern Skagerrak Enriched? Journal of Experimental Marine Biology and Ecology, 105, $219-251$. http://dx.doi.org/10.1016/0022-0981(87)90174-2

[9] Rosenberg, R. and Nilsson, H.C. (2005) Deterioration of Soft-Bottom Benthos along the Swedish Skagerrak Coast. Journal of Sea Research, 54, 231-242. http://dx.doi.org/10.1016/j.seares.2005.04.003

[10] Théel, H. (1907) Om utvecklingen af Sveriges zoologiska hafsstation Kristineberg och om djurlifvet i angränsande haf och fjordar (On the Development of Sweden's Zoological Sea Station Kristineberg and about the Animals in Adjacent Sea and Fjords). Arkiv för Zoologi, 4, 1-136.

[11] Svansson, A. (1975) Physical and Chemical Oceanography of the Skagerrak and the Kattegatt. Fishery Board of Sweden, 1, 1-88.

[12] Hansson, H.G. (1994) Sydskandinaviska marina flercelliga evertebrater. Länsstyrelsen i Göteborgs och Bohus län, 15, $205 \mathrm{p}$.

[13] Molander, A. (1963) The Fauna in the Fjords of Bohuslän. Arkiv för Zoologi, 15, 1-64.

[14] Rosenberg, R. and Möller, P. (1979) Salinity Stratified Benthic Macrofaunal Communities and Long-Term Monitoring along the West Coast of Sweden. Journal of Experimental Marine Biology and Ecology, 37, 175-203. http://dx.doi.org/10.1016/0022-0981(79)90094-7

[15] Gislén (1928) Epibiosis of the Gullmar Fjord 1-2. Kristinebergs Zoologiska Station, 1877-1927.

[16] Jägerskiöld, L.A. (1971) A Survey of the Marine Benthonic Macro-Fauna along the Swedish West Coast 1921-1938. Acta Regiae Societatis Scientiarum et Litterarum Gothoburgensis. Zoologica, No. 6, 146 p.

[17] Johansson, G., Eriksson, B.K., Pedersén, M. and Snoeijs, P. (1998) Long-Term Changes of Macroalgal Vegetation in the Skagerrak Area. Hydrobiologia, 385, 121-138. http://dx.doi.org/10.1023/A:1003405826222

[18] Pihl, L., Svenson, A., Moksnes, P.-O. and Wennhage, H. (1999) Distribution of Green Algal Mats Throughout Shallow Soft Bottoms of the Swedish Skagerak Archipelago in Relation to Nutrient Sources and Wave Exposure. Journal of Sea Research, 41, 281-294. http://dx.doi.org/10.1016/S1385-1101(99)00004-0

[19] Pihl, L., Isaksson, I., Wennhage, H. and Moksnes, P.-O. (1995) Recent Increase of Filamentous Algae in Shallow Swedish Bays: Effects on the Community Structure of Epibenthic Fauna and Fish. Netherlands Journal of Aquatic Ecology, 29, 349-358. http://dx.doi.org/10.1007/BF02084234

[20] Isaksson, I., Pihl, L. and van Montfrans, J. (1994) Eutrophication-Related Changes in Macrovegetation and Foraging of Young Cod (Gadus morhua L.): A Mesocosm Experiment. Journal of Experimental Marine Biology and Ecology, 177, 203-217. http://dx.doi.org/10.1016/0022-0981(94)90237-2

[21] Rosenberg, R., Agrenius, S., Hellman, B., Nilsson, H.C. and Norling, K. (2002) Recovery of Benthic Habitats and Fauna in a Swedish Fjord Following Improved Oxygen Conditions. Marine Ecology Progress Series, 234, 43-53. http://dx.doi.org/10.3354/meps234043 
Scientific Research Publishing (SCIRP) is one of the largest Open Access journal publishers. It is currently publishing more than 200 open access, online, peer-reviewed journals covering a wide range of academic disciplines. SCIRP serves the worldwide academic communities and contributes to the progress and application of science with its publication.

Other selected journals from SCIRP are listed as below. Submit your manuscript to us via either submit@scirp.org or Online Submission Portal.
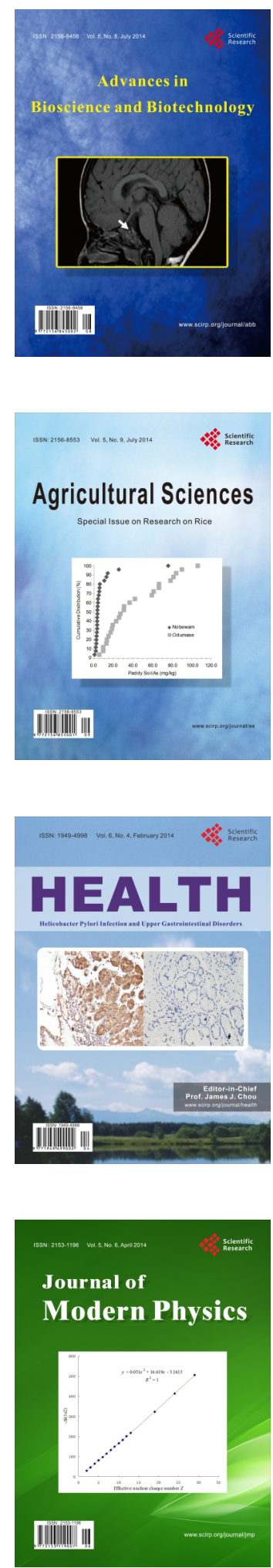
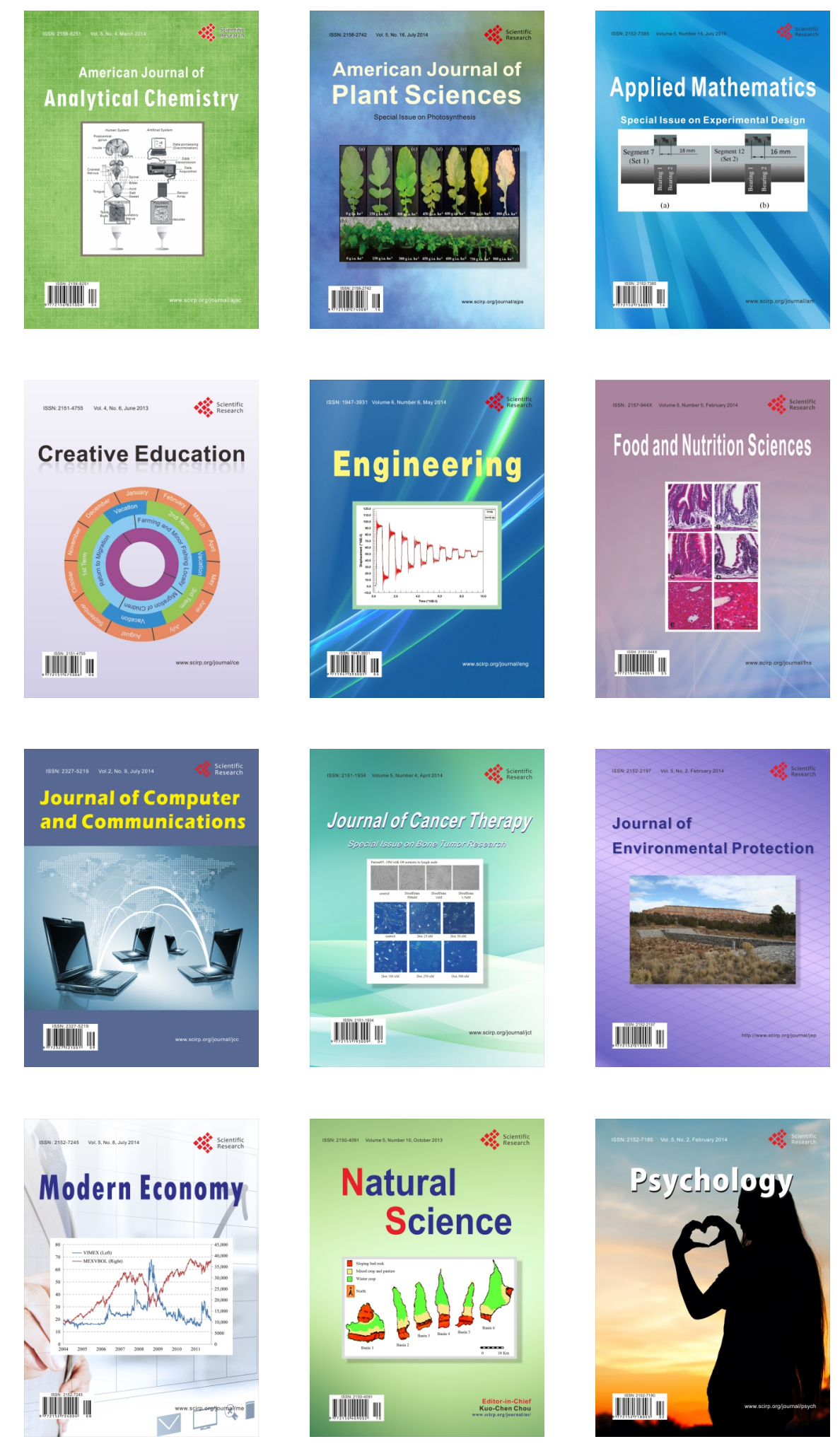